\title{
Targeted therapy in head/neck and gastric cancers
}

\author{
Chung-Tsen Hsueh \\ From New developments in Hematology and Oncology in 2011 \\ Guangzhou, China. 25-26 December 2011
}

The epidermal growth factor receptor (EGFR/HER1) is a member of the erbB family of receptor tyrosine kinase proteins, which also includes HER2, HER3, and HER4. EGFR is almost universally expressed in squamous cell carcinoma of head and neck (SCCHN), and high levels of expression have been correlated with a poor clinical prognosis [1]. Cetuximab, an IgG1 monoclonal antibody against EGFR, has demonstrated improved survival and disease control when used in combination with radiation therapy for the treatment of locally advanced SCCHN, and in combination with platinum-based chemotherapy in recurrent or metastatic SCCHN [2-4]. Additionally, single-agent cetuximab is active and provides good disease control rate and duration in platinum-refractory SCCHN [5]. Comparison of cetuximab versus cisplatin concurrently with radiotherapy is under investigation in patients with human papillomavirus-associated oropharyngeal cancer, who have better prognosis and may benefit from less toxic treatment [6].

Overexpression of HER2 in gastric cancer results in aggressive clinical course and poor prognosis [7]. Trastuzumab, a monoclonal antibody against HER2, exhibits antitumor activity in HER2 overexpressed gastric cancer cells, and enhances effects of chemotherapy in gastric cancer xenograft overexpressing HER2 [8]. The ToGA study screened about 3,800 patients with advanced gastric cancer from 24 countries, and HER2 overexpression was detected in 22\% [9]. Higher rates of HER2 overexpression occurred in intestinal and proximal or gastroesophageal junction cancers than in diffuse or distal gastric cancers. In TOGA study, 584 patients with HER2 overexpression were randomized to receive fluoropyrimidine and cisplatin treatment with or without trastuzumab. Patients who received trastuzumab plus chemotherapy achieved longer overall survival (13.8 months vs. 11.1 months, $\mathrm{P}=0.0046)$,

Correspondence: chsueh@llu.edu

Loma Linda University, Loma Linda, CA 92354, U.S.A longer progression-free survival (6.7 months vs. 5.5 months, $\mathrm{P}=0.0002)$, and higher response rates $(47 \%$ vs. $35 \%, \mathrm{P}=0.0017)$ than those who received chemotherapy alone. Complete response was noted in $5.4 \%$ of patients receiving trastuzumab plus chemotherapy vs. $2.4 \%$ in chemotherapy alone. There were no significant differences in the toxicities between these two groups. This study has established a new paradigm using trastuzumab in combination with chemotherapy in patients with advanced gastric cancer overexpressing HER2.

Neoadjuvant treatment is a standard of care for locally advanced esophageal and gastric cancer. We have previously reported a case of pathological complete response after neoadjuvant chemotherapy with trastuzumab-containing regimen in HER2-overexpressing gastric cancer [10]. Incorporating trastuzumab as a part of neoadjuvant therapy in esophageal and gastric adenocarcinoma overexpressing HER2 is currently under active investigation. Radiation Therapy Oncology Group is conducting a phase III neoadjuvant study in patients with HER2-overexpressing esophageal adenocarcinoma to determine if trastuzumab increases disease-free survival when added to chemoradiotherapy [11]. Other studies conducted in Europe are adding trastuzumab to oxaliplatin-based regimen as perioperative chemotherapy for HER2-overexpressing esophagogastric or gastric adenocarcinoma, and looking for improvement of pathological complete response and disease-free survival $[12,13]$.

Pertuzumab is a monoclonal antibody interfering with HER2 dimerization with other HER receptors such as EGFR, HER3 and HER4. Pertuzumab and trastuzumab bind to HER2 at different sites, and combination of both antibodies leads to stronger inhibition of erbB signaling and greater therapeutic efficacy when combined with docetaxel in breast cancer [14]. Combination of pertuzumab and trastuzumab with platinum-based chemotherapy is 
currently studied in HER2-overexpressing gastric cancer [15].

Published: 25 April 2012

\section{References}

1. Ang KK, Berkey BA, Tu X, Zhang HZ, Katz R, Hammond EH, Fu KK, Milas L: Impact of epidermal growth factor receptor expression on survival and pattern of relapse in patients with advanced head and neck carcinoma. Cancer Res 2002, 62(24):7350-7356.

2. Bonner JA, Harari PM, Giralt J, Azarnia N, Shin DM, Cohen RB, Jones CU, Sur R, Raben D, Jassem J, et al: Radiotherapy plus cetuximab for squamous-cell carcinoma of the head and neck. N Engl J Med 2006, 354(6):567-578.

3. Bonner JA, Harari PM, Giralt J, Cohen RB, Jones CU, Sur RK, Raben D, Baselga J, Spencer SA, Zhu J, et al: Radiotherapy plus cetuximab for locoregionally advanced head and neck cancer: 5 -year survival data from a phase 3 randomised trial, and relation between cetuximabinduced rash and survival. Lancet Oncol 2010, 11(1):21-28.

4. Vermorken JB, Mesia R, Rivera F, Remenar E, Kawecki A, Rottey S, Erfan J, Zabolotnyy D, Kienzer HR, Cupissol D, et al: Platinum-based chemotherapy plus cetuximab in head and neck cancer. N Engl J Med 2008, 359(11):1116-1127.

5. Vermorken JB, Trigo J, Hitt R, Koralewski P, Diaz-Rubio E, Rolland F, Knecht R, Amellal N, Schueler A, Baselga J: Open-label, uncontrolled, multicenter phase II study to evaluate the efficacy and toxicity of cetuximab as a single agent in patients with recurrent and/or metastatic squamous cell carcinoma of the head and neck who failed to respond to platinum-based therapy. J Clin Oncol 2007, 25(16):2171-2177.

6. Phase III trial of radiotherapy plus cetuximab versus chemoradiotherapy in HPV-associated oropharynx cancer (clinicaltrials.gov identifier: NCT01302834). [http://clinicaltrials.gov/ct2/show/NCT01302834].

7. Park D, Yun J, Park J, Oh S, Kim H, Cho Y, Sohn C, Jeon W, Kim B, Yoo C, et al: HER-2/neu Amplification Is an Independent Prognostic Factor in Gastric Cancer. Digestive Diseases and Sciences 2006, 51(8):1371-1379.

8. Fujimoto-Ouchi K, Sekiguchi F, Yasuno H, Moriya Y, Mori K, Tanaka Y: Antitumor activity of trastuzumab in combination with chemotherapy in human gastric cancer xenograft models. Cancer Chemotherapy and Pharmacology 2007, 59(6):795-805.

9. Bang YJ, Van Cutsem E, Feyereislova A, Chung HC, Shen L, Sawaki A, Lordick F, Ohtsu A, Omuro Y, Satoh T, et al: Trastuzumab in combination with chemotherapy versus chemotherapy alone for treatment of HER2positive advanced gastric or gastro-oesophageal junction cancer (ToGA): a phase 3, open-label, randomised controlled trial. Lancet 2010, 376(9742):687-697.

10. Wang J, Saukel GW, Garberoglio CA, Srikureja W, Hsueh CT: Pathological complete response after neoadjuvant chemotherapy with trastuzumabcontaining regimen in gastric cancer: a case report. $J$ Hematol Oncol 2010, 3:31.

11. A phase III trial evaluating the addition of trastuzumab to trimodality treatment of HER2-overexpressing esophageal adenocarcinoma (clinicaltrials.gov identifier: NCT01196390 ). [http://clinicaltrials.gov/ct2/ show/NCT01196390].

12. HerFLOT: Multicenter, explorative phase II study of perioperative 5-FU, leucovorin, docetaxel, and oxaliplatin in combination With trastuzumab in patients With HER2-positive, locally advanced, resectable adenocarcinoma of the gastroesophageal junction or stomach (clinicaltrials.gov identifier: NCT01472029). [http://clinicaltrials.gov/ct2/ show/NCT01472029].

13. An open-label, multi-center study to evaluate the disease free survival rate of a perioperative combination of capecitabine (xeloda), trastuzumab and oxaliplatin (XELOX- Trastuzumab) in patients with resectable gastric or gasro-esophageal junction adenocarcinoma (clinicaltrials.gov identifier: NCT01130337). [http://clinicaltrials.gov/ct2/ show/NCT01130337].

14. Baselga J, Cortes J, Kim SB, Im SA, Hegg R, Im YH, Roman L, Pedrini JL, Pienkowski T, Knott A, et al: Pertuzumab plus trastuzumab plus docetaxel for metastatic breast cancer. N Engl J Med 2011, 366(2):109-119.
15. An open-label, randomized, multicenter phase lla study evaluating pertuzumab in combination with trastuzumab and chemotherapy in patients with HER2-positive advanced gastric cancer (clinicaltrials.gov identifier: NCT01461057). [http://clinicaltrials.gov/ct2/show/NCT01461057].

doi:10.1186/1756-8722-5-S1-A1

Cite this article as: Hsueh: Targeted therapy in head/neck and gastric cancers. Journal of Hematology \& Oncology 2012 5(Suppl 1):A1.

\section{Submit your next manuscript to BioMed Central and take full advantage of:}

- Convenient online submission

- Thorough peer review

- No space constraints or color figure charges

- Immediate publication on acceptance

- Inclusion in PubMed, CAS, Scopus and Google Scholar

- Research which is freely available for redistribution 